\title{
Rituales, sacrificios y sacerdocio en la India antigua
}

\author{
Ritual, Sacrifice and Priesthood \\ in Ancien India
}

MARÍA TERESa ROMÁN LÓPEZ*

\begin{abstract}
RESUMEN
El núcleo de la actividad religiosa del vedismo era el sacrificio y el correspondiente alimento sacrificial que compartían los diversos integrantes del grupo y ciertas entidades sobrehumanas.

Podemos clasificar los ritos védicos en dos grandes apartados: privados o domésticos y solemnes. Algunos estudiosos llegarán a afirmar que todo depende del sacrificio.
\end{abstract}

PALABRAS CLAVE:

Ritual, vedismo, sacrificio, ritos védicos, los sacerdotes.

\begin{abstract}
The nucleus of vedic religious activity was sacrifice and the corresponding food sacrifice that the different members of the group and certain superhuman entities share. We can classify vedic rites in two broad ways: private or domestic and solemn. Some scholars will state that every thing depends on the sacrifice.
\end{abstract}

\section{KEYWORDS:}

Ritual, Vedism, Sacrifice, Vedic rituals, Priests.

\section{INTRODUCCIÓN}

El corazón de la actividad religiosa del vedismo era el sacrificio y el correspondiente alimento sacrificial que compartían los diversos integrantes del grupo y ciertas entidades sobrehumanas. Su aspecto más sobresaliente era el acto de ofrenda al fuego. Por medio del sacrificio, las deidades pueden ser apaciguadas, se puede conseguir que derramen sobre el oferente ciertos favores, como descen-

* Profesora-Titular del Departamento de Filosofía. Facultad de Filosofía. UNED. E-mail: mroman@ fsof.uned.es. 
dencia o ganado, y se pueden modificar la categoría social y el poder o la pureza del que ha encargado y sufragado el sacrificio. Tales prácticas religiosas no requerían santuarios, templos, imágenes o textos sagrados ${ }^{1}$, lo cual quizá se deba a un modo de vida nómada.

Dada la diferente disposición de aquellos que deseaban impetrar, por medio del sacrificio, gracias y beneficios de los dioses, distintos debieron de ser también los rituales relacionados con la solemnidad del sacrificio desde los tiempos más antiguos. El universo ritual del vedismo es tan rico y está tan minuciosamente detallado que no vamos a referir aquí más que algunas de sus peculiaridades ${ }^{2}$.

Podemos clasificar los ritos védicos en dos grandes apartados: privados 0 domésticos (grihya) y solemnes ( rauta) ${ }^{3}$ : «Les Çrautasûtras déclarent reposer sur la Çruti (c'est-à-dire l' «Audition» de la vérité éternelle par des sages inspirés des premiers temps), les Grhya et Dharmasûtras reposent sur la Smrti «Mémoire», donc tradition) et n'ont d'autorité que parce qu'ils son en accord avec la Çruti. Le maniement des rites grhyas, beacoup moins compliqués, n'exigeait pas des spécialistes comme celui des rites çrautas ${ }^{4}$.

Llegará a afirmarse que todo depende del sacrificio; ante su enorme poder se inclinan reverentes los dioses, a quienes el sacrificio alimenta, y en cuyo nombre imponen su querer. Ante esta situación no es difícil comprender que en el desarrollo del sacrificio, práctica cada vez más solemne y compleja, se pusiera el mayor empeño para que no hubiera ni el más mínimo fallo. No resulta extraño pues que el Yajur-Veda Saṃhitā («Veda de las fórmulas sacrificiales») ${ }^{5}$, esté dedicado precisamente a la práctica sacrificial. Con el transcurso del tiempo, voluminosas obras se sumarán a los $V_{e d a}{ }^{6}$ con el objetivo de revelar los pormenores de la actividad

1 «Le culte védique ne comportait pas de temples. Les cérémonies avaient lieu soit Dans la maison de celui que prenait l'initiative du sacrifice, soit sur un terrain avoisinant, où celui-ci (au sud du feu âhavanîya), sa femme et le prêtre brahmane prenaient place; le lit sacrificiel (vedi), morceau du champ légèrement creusé et recouvert ensuite d'herbe à sacrifices (barhis), se trouvait au milieu. Sur cette vedi on installait les offrandes et l'on imaginait les dieux invités assis sur ce «lit», en train de les manger». J. Gonda, Les religions de L'Inde. Vedisme et hindouisme ancien, Payot, vol. I, París, 1962, p. 172.

2 Cf. M. Biardeu y C. Malamoud, Le sacrifice dans l'Inde ancienne, PUF, París, 1976.

3 Cf. A.B. Keith, The religión and philosophy of the Veda and Upanishads, Greenwood Press, vol. II, Westport, Connecticut, pp. 313-378.

4 J. Gonda, ob. cit., p. 132.

5 El Yajur-Veda está integrado por dos variedades de «colecciones»: Yajur-Veda blanco y YajurVeda negro y se compone de versos originales y de otros tomados del Rg-Veda, con fórmulas en prosa, para que el sacerdote pueda desempeñar sus actividades litúrgicas. Éstas se refieren a los instrumentos del sacrificio, cuya función y valor místicos va gradualmente explicando. El sacrificio se reafirma gracias a este Veda, como algo de gran importancia, medio eficaz para exigir a la deidad una mayor atención a cualquier demanda del sacrificador, ante el cual palidece su ya debilitada potencia, mientras brilla el poder del sacerdote.

6 Veda es una palabra sánscrita que significa «saber, conocimiento». Se refiere a cada uno de los libros sagrados primitivos de la India, escritos en védico. La literatura védica está constituida por una primera sección correspondiente a las cuatro Colecciones que son: Rig-Veda Samhitā («Colección de los Himnos»); Yajur-Veda Saṃhitā («Colección de las Fórmulas Rituales»); Sāma-Veda Saṃhitā («Colección de las Melodías») y Atharva-Veda Saṃhitā («Colección de los Himnos Mágicos»). La segunda sección está compuesta por los Brāhmaṇa, los Āranyaka y las Upanișad. Cf. H. Oldenberg, La literatura de la antigua India, Losada, Buenos Aires, 1956, pp. 7-62. 
sacrificial. En efecto, en los Brāhmaṇa ${ }^{7}$, el sacrificio será sometido a una exégesis escrupulosa, estableciendo su valor esencial y su significado exacto.

La institución del sacrificio védico supuso uno de los más antiguos ensayos llevados a cabo en el subcontinente por atribuir al sistema de doctrinas, concepciones y usos religiosos una forma organizada y precisa. Todavía más, un sacrificio védico representaba una significativa voluntad de cooperación que implicaba a los distintos niveles de la sociedad y que favorecía un determinado sentido de ayuda y confraternización entre ellos. Sin embargo, la preocupación exagerada de los responsables del sistema ritual por las intrincadas y sofisticadas manipulaciones de la ceremonia sacrificial contribuyó en gran medida a eclipsar la fisonomía de los valores subyacentes al sacrificio del vedismo:

«En el periodo brahmánico, el sacrificio fue exaltado de manera tan extravagante que llegó a ser considerado no ya como un medio tendente a un fin, sino como un fin en sí mismo. No sólo se convirtió el sacrificio en la piedra angular sobre la que se apoyaba todo el edificio de la vida comunitaria del pueblo védico, sino que fue elevado a la condición de fuerza motriz básica de todos los fenómenos cósmicos. De ahí se derivó con toda naturalidad una situación en que los sacerdotes, que tenían en sus manos la clave de la teoría y la práctica del sacrificio, ejercieron sobre toda la comunidad una influencia intelectual y social que prácticamente equivalía a una dominación [...]. Surgió un grupo formado por pensadores libres que rechazaron la actitud de aceptación ciega, que los sacerdotes habían fomentado más o menos deliberadamente entre el pueblo, y trataron de sustituirla por una actitud de investigación sin trabas [...]. Comenzaron por poner en tela de juicio los dos presupuestos básicos de los Brāhmanas [...]. El sacrificio, insistían estos pensadores, era un barco inseguro en el que no resultaba sensato confiar demasiado para cruzar con éxito el océano peligroso de la existencia mundana. De hecho, esta

\footnotetext{
7 «Hacia finales del periodo samhítico, los arios védicos habían logrado ya prácticamente la estabilidad política y la seguridad económica, y se hallaban socialmente organizados. El paso de una vida azarosa, aventurera y nómada a una existencia que contaba con las comodidades de un hogar no dejó de influir en su religiosidad, y más que nada en sus prácticas religiosas. Además de las sencillas plegarias, del culto al fuego y de los ritos del Soma, así como de la magia primitiva, se fue desarrollando un sistema ritual muy complicado, que pronto llegaría a ser la única forma reconocida de religiosidad. Se fijaron normas muy minuciosas y absolutamente obligatorias en relación con los distintos pormenores del ritual, tales como las del lugar y tiempos adecuados para el sacrificio, los fuegos sagrados, los sacerdotes oficiantes, las materias y utensilios aptos para ser empleados en el culto sacrificial, las divinidades, las ofrendas, los mantra y daksinā, así como los ritos de reparación y expiación por los errores o las omisiones cometidos durante el rito sacrificial. Consecuencia lógica de todo ello fue que a partir de aquel momento la iniciativa y la capacidad de actuación en los asuntos religiosos pasaron, a todos los efectos prácticos, a manos de la clase, recién constituida, de sacerdotes profesiones que se arrogaban la condición de expertos en las prácticas rituales y que, en consecuencia, se suponían en condiciones de guiar al pueblo con autoridad en el cumplimiento de sus deberes sacrificiales. Debió de sentirse además la necesidad de unos manuales que describiesen los numerosos detalles teóricos y prácticos de aquel sistema sacrificial tan complicado. De esa necesidad surgió, ciertamente, el conjunto de textos llamados Brāhmana. Su tema central son los ritos. También el Yajurveda y el Sāmaveda, a pesar de que tradicionalmente son considerados Samhitas, son de carácter ritual, directamente el primero y el segundo desde el punto de vista del fin a que servía, mientras que los Srauta-Sūtras, que realmente pertenecen al periodo posupanisádico, tratan de consolidar y sistematizar las doctrinas de los Brāhmana. Todos estos textos, en consecuencia, han de ser considerados representantes de la ideología religiosa del periodo brahmánico, al menos desde un punto de vista conceptual». R. N. Dandejar, «Hinduismo», en C. J. Bleeker y G. Widengren, Historia religionum, Cristiandad, vol. II, Madrid, 1973, p. 258.
} 
existencia mundana, incluyendo el macrocosmos y el microcosmos, era precisamente una ficción creada por la ignorancia; era el resultado de una superposición errónea de la multiplicidad a la realidad suprema subyacente que era una y única. Esta toma de conciencia mística de la propia identidad con la realidad única y definitiva -el anegamiento de la propia individualidad en la totalidad cósmica- se puso como objetivo supremo de todas las prácticas religiosas y especulaciones filosóficas. Al mismo tiempo se estableció que cada cual era libre -intelectual y socialmente para seguir su propio camino solitario hacia ese fin. Tal es la nueva tendencia religioso-filosófica que se refleja en las Upanisades ${ }^{8} . »$

En este breve artículo describiremos algunas de las facetas más reveladoras del sacrificio, la práctica religiosa nuclear del vedismo o religión del Veda que, en buena medida, pueden ayudarnos a entender algunas de las razones que justifican el papel de primer orden que ha tenido y que aún tiene en la India ${ }^{10}$. El carácter sumario de la exposición nos ha obligado a presentar, mucho más simples de lo que son, los hechos, los problemas y los múltiples factores que giran en torno al ritual sacrificial de los arios védicos. Dada, pues, la imposibilidad de ofrecer una información completa y pormenorizada, hemos convertido nuestra tarea en una fructífera aproximación.

\section{RITOS DOMÉSTICOS}

Los conocimientos de los ritos domésticos proceden en buena medida de los Gṛhya-Sūtra [«las reglas (para las ceremonias) domésticas»]; estos rituales cubren la totalidad de la existencia, desde la concepción hasta la muerte ${ }^{11}$ y se celebraban en la casa del que efectuaba el sacrificio, es decir la persona que lo había encargado (y pagado); no se limita a la inmolación o «asesinato ritual» de animales domésticos (cabras, caballos, toros, vacas, carneros, etc.), sino que se refiere de forma más amplia a cualquier ofrenda al fuego sagrado, especialmente leche, manteca, cuajada, cereales, pastelillos y la planta soma. Estas ofrendas rituales llegan a través del fuego, aspecto nuclear del ritual védico y cuya «institución» misma constituye una ceremonia autónoma. El fuego que se requería para estas actividades recibía el nombre de gārhapatya [fuego (agni) del dueño de casa»]:

8 Ibíd, pp. 260-261.

9 «Es frecuente el uso de expresiones como «vedismo» y «religión védica» para designar el tipo de religiosidad que se refleja en los himnos védicos». S. G. Brandon, Diccionario de religiones comparadas, Cristiandad, vol. II, Madrid, 1975, p. 1451.

10 «Entre algunos brahmanes, sobre todo en algunas familias nambudri de Kerala, estudiadas por Frits Staal, los rituales rauta han permanecido intactos desde por lo menos el periodo de los rauta Sūtras hasta la actualidad». G. Flood, El hinduismo, Cambridge University Press, Madrid, 1998, p. 56.

11 «Entre los ritos privados, aparte del mantenimiento del fuego doméstico y las fiestas agrícolas, los más importantes son los «sacramentos» o «consagraciones» (samskāra) en relación con la concepción y el nacimiento de los niños, la presentación (upanayama) del muchacho a su preceptor brahmán, el matrimonio y los funerales. Se trata de ceremonias muy sencillas: ofrendas y dones vegetales y, para los "sacramentos», gestos rituales acompañados de fórmulas musitadas por el dueño de la casa». M. Eliade, Historia de las creencias y de las ideas religiosas. De la prehistoria a los misterios de Eleusis, Cristiandad, vol. I, Madrid, pp. 231-232. 
«Le feu sert d'intermédiaire entre le sacrifiant et la divinité, c'est le véhicule de l'offrande, mais à l'origine c'était d'abord un agent magique de purification, écartant les mauvais esprits, comme l'attestent encore maints détails, notamment Dans le culte privé. On n'offrait primitivement pas dans le feu, mas à terre, sur una jonchée (plus tard aussi Dans l'eau, en l'air ou Dans la terre), comme il est demeuré d'usage dans le culte des morts [...]. Mais enfin la fonction dominante est celle du feu sacrificiel, et tout le rituel védique repose sur l'institution du feu.

Une distinction capitale a eu lieu entre a) le sacrifice à un seul feu, peut-être le plus ancien et sourtout prope aux cérémonies privées exécutées par le maître de maison et b) le sacrifice à trois feux, propre au culte solennel et surtout aux sacrifices du soma où sans doute il a pris naissance (KNAUER). En tête, seul nomé dans le $R k$, le feu «du maître de maison (gârhapatya), survivant de l'antique foyer domestique, le seul qu'on entretienne perpétuellement et auquel on emprunte de quoi allumer les deux autres; de forme ronde, le foyer gárhapatya sert surtout à la cuisson des offrandes. A l'Est du précédent le feu «oblatoire» (âhavanîya), de forme carrée où l'on verse l'oblation cuite. A Sud le feu «du mets à apporter en fin (de cérémonie pour la daksina)» (anvâhâryapacana) ou feu "du Sud» (daksinâgni), en forme de demi-lune» ${ }^{12}$.

\section{RITOS SOLEMNES}

Todo lo referente a eventos que iban más allá del ámbito doméstico era objeto de mayor solemnidad ritual ${ }^{13}$. Hasta los más mínimos detalles del ceremonial eran considerados fruto de la revelación (śrutt) ${ }^{14}$. La información que poseemos de los rituales solemnes procede sobre todo de los rauta Sūtra formulados entre los siglos VIII y IV. Los sacrificios tenían lugar en un lugar próximo al domicilio del sacrificador y exigían la presencia de varios oficiantes: «El laico asiste al sacrificio en compañía de su esposa; pronuncia, incluso, algunas fórmulas, pero su papel esencia es el de distribuir los honorarios (que pueden alcanzar proporciones fabulosas) correspondientes a los diversos oficiantes ${ }^{15}$.

12 L. Renou y J. Filliozat, Inde Classique, Librairie d'Amérique et d'Orient, tomo 1, París, 1985, pp. 347-348.

13 «El rito solemne más breve es el Agnihotra u «oblación al fuego»: simple ofrenda de leche a Agni, ejecutada por el sacerdote manual y el laico, a la mañana y al anochecer. Más complejo es el sacrificio de plenilunio y novilunio, como el de las oblaciones vegetales, que sirve de norma a todas las demás y requiere dos oficiantes [...]. El sacrificio animal, la inmolación (por asfixia) de un macho cabrío, también se inspira en el anterior, y figura con carácter independiente o como parte integrante de los sacrificios de soma». L. Renou, El hinduismo, Paidós Orientalia, Barcelona, 1991, p. 20.

14 Literalmente, «audición», «oído»; comprende textos que se refieren a la escucha por parte de los rși, videntes-poetas de antaño. Estos sabios inspirados por las deidades eran el medio para transmitir a la posteridad la información que recibieron. La verdad contenida en la ruti es al mismo tiempo eterna e impersonal, y está contenida en los Veda, cada uno de los cuales lleva el nombre genérico de saṃhitā, es decir, «colección» o «recopilación»: «"Como gozosos torrentes que brotan de las montañas" -símil tomado del Veda-, los cantos de los sabios surgían espontáneamente, como revelaciones de lo real. En consecuencia, Veda es un nombre significativo: quiere decir sabiduría revelada, conocimiento metafísico». T. M. P. Mahadevan, Invitación a la filosofía de la India, Fondo de Cultura Económica, México, 1991, p. 17.

15 L. Renou, ob. cit., p. 19. 
El oficiante más importante era el hotar, sacerdote sacrificador y cantor; el adhvaryu era el encargado de los pormenores del sacrificio; por último, el brahmán, supervisor silencioso del culto, sólo interviene cuando se produce algún fallo en el sistema ritual, ejecutando entonces la obligada reparación. Un espacio cuadrangular se convertía en una suerte de altar (vedi), sobre el cual se extendía una alfombra de hierba verde (barhis), en la que, a modo de mullido asiento, se sentaban las divinidades invitadas al sacrificio para participar y gozar de las ofrendas. Cerca del altar se colocaban los tres fuegos, en puntos cardinales distintos. Al oeste, el gārhapatya, fuego que se encendía en primer lugar y servía para los usos domésticos y para alejar del sacrificador y de su familia cualquier tipo de mal procedente de los hombres. Un segundo fuego denominado āhavanīya se colocaba en la zona este del altar y en él se arrojaban las ofrendas. Y al sur, se situaba el tercero llamado dakșināgni con el objetivo de ahuyentar a los espíritus malvados. Las deidades principales que constituían el foco de las prácticas rituales rauta eran Soma, el dios-planta ${ }^{16}$ y Agni, la deidad del fuego.

Entre los sacrificios védicos de mayor relieve figura el a maveda («sacrificio del caballo») ${ }^{17}$ : un sacrificio regio (o, más precisamente, por líderes de los clanes que gobernaban los numerosos y pequeños reinos que constituían la India en la antigüedad), en el que el monarca, sometido previamente a ritos dirigidos a des-

16 Soma, planta de propiedades excitantes, de índole bastante misteriosa. Algunos la identifican con la Sarcostemma viminale, o con la Asclepias acida (Sarcostemma brevistigma) y otros con la Sarcostemma acidum; hay quienes ven en el soma la caña de azúcar u otra planta cualquiera. Según R. Gordon Wasson: «Soma es the Divine Mushroom of Inmortality, and that the early days of our culture, before we made use of redding and writing, when the $R g$-Veda was being composed, the prestige of this miraculous mushroom ran by word of mouth far and wide throughout Eurasia, well beyond the regions where it grew was worshipped». Soma. Divine mushroom of inmortality, Harcourt Brace Jovanovich, INC., Nueva York, 1964, p. 8. En el Rg-Veda hay un himno dedicado a soma, en su doble aspecto de la planta sagrada y de la deidad que la encarna, y del que reproducimos un breve fragmento: «Generoso soma, señor de las regiones celestiales, mana desde Aryika en toda tu pureza, exprimido con la palabra santa y la verdad, con la fe y el ascetismo. Fluye por doquiera para Indra, oh soma». F. Tola (ed.), Himnos del Rig Veda, Sudamericana, Buenos Aires, 1968, p. 170. También de los Veda proviene el siguiente relato acerca de soma: «En algunos pasajes se dice que la planta había sido traída desde una montaña regalada a Indra. En otros, que el rey Soma había vivido entre los Gandharvas, una raza de semi-dioses que forman el coro del cielo de Indra. Los dioses, conociendo las virtudes de este rey o planta -pues ambos términos parecen ser aplicados indiscriminadamente- desearon obtenerla. No sabiendo cómo conseguirla, Vach (la diosa del habla) dijo: «Los Gandharvas son aficionados a las mujeres; dejadme que vaya y la obtendré para vosotros». Los dioses dijeron: «Pero, ¿cómo podremos pasarnos sin ti? » Ella contestó: «Primero consigamos el dios, luego regresaré a vosotros siempre que me necesitéis».

Otra versión de este lance es que mientras los dioses vivían en la tierra. Soma estaba en el cielo. Deseando poseerla, enviaron a Gayatri (nombre dado a la esposa o hija de Brahma) a por la planta. Ella partió en forma de pájaro y regresaba ya con ella cuando los Gandharvas se la quitaron; éstos sólo se la dejaron arrebatar cuando la diosa Vach se presentó ante ellos como se ha narrado anteriormente.

Cuando se ofreció el Soma a los dioses, surgió una disputa sobre quién debería beber el primer trago. Al final se decidió mediante una carrera. Vayu llegó primero a la meta, siendo Indra el segundo. Indra se esforzó mucho en ganar y cuando se hallaban cerca del poste que indicaba la meta propuso que llegaran a ella juntos y que Vayu tomaría dos tercios de la bebida. Vayu dijo: «¡Ni hablar! Yo seré el único ganador». Entonces Indra dijo: «jEntremos juntos en la meta y dame una cuarta parte de la divina bebida!» Vayu accedió a ello y de este modo fu compartido por ellos dos». W. J. Wilkins, Mitología hindú, Edicomunicación, Barcelona, 1987, p. 81.

17 Un estudio amplio y riguroso del tema en P. E. Dumont, L'Aśvamedha: description du sacrifice solennel du cheval dans le culte védique d'après les textes du Yajurveda blanc, Geuthner, París, 1927. 
tacar su poder (unción, coronación, consagración real, bebida del vigor), solicitaba a la divinidad esplendor imperial, descendencia masculina y grandes victorias en las batallas. La ceremonia tenía lugar en la primavera o en el verano y duraba alrededor de un año e incluía un semental, otro centenar de caballos, jóvenes guerreros y una importante inversión económica. Al finalizar el año, el semental era sacrificado y las ceremonias culminaban cuando la reina principal simulaba una cópula con el caballo sacrificado:

«La solemne ceremonia tenía lugar en la primavera o en el estío; en el primer caso, en el día octavo de la quincena creciente del mes de Phālguna (15 de febrero-15 de marzo) y duraba más de un año. El rey se apresta al sacrificio después de haber observado el primer día silenciosa vigilia, terminada la cual, un semental, cuidadosamente seleccionado [...] era conducido al lugar del sacrificio y sometido a un baño purificador, «que lo consagraba para su santo destino». Terminados estos ritos iniciales, un hombre, de ínfima clase, mataba de una mazada en la cabeza un perro de cuatro ojos (dos pintados encima de los dos naturales) el cuerpo del perro se sumergía en el agua que había servido para el baño del caballo, como para alejar, con los cuatro vigilantes ojos del animal, toda influencia maligna del corcel destinado al sacrificio. Luego se le abría la puerta, camino del noreste, dejándolo vagar libremente un año entero, durante el cual más de cuatrocientos jinetes de sangre real, nobles y militares, vigilaban los movimientos del caballo, para defenderlo de eventuales enemigos, sin perderle jamás de vista, caso, éste, suficiente para que el ceremonial se debiese empezar de nuevo. Durante el vagar del caballo se celebraban fiestas solemnes, y sobre el lugar del futuro sacrificio se ofrendaban oblaciones simbólicas, y se narraban historias de los antepasados del rey, cuyas gestas eran celebradas, ejecutándose al mismo tiempo cantos y melodías.

Transcurrido un año, comienza el verdadero sacrificio con la dīkșā real; la ceremonia duraba tres días, durante los cuales se sacrificaban, a la parte oriental, multitud de animales y tenía lugar la presión de soma. Al amanecer del día segundo el caballo apresado se le somete a infinitas ceremonias litúrgicas (uncimiento a un carro de oro, atavío con diversos ornamentos, ofrenda de granos especiales, un segundo baño, unción, etc.) y atado, solo en los tiempos antiguos o acompañado de numerosas víctimas más tarde, se le sofoca entre finísimas telas. La primera reina se acostaba junto a él cubierta con un mismo manto, simbolizando así la certeza en la prole futura del rey y en la adquisición de todas las nobles cualidades distintivas del caballo sacrificado; en el ínterin, las restantes esposas del rey y los sacerdotes, mujeres y niños, se cambiaban entre sí bromas no siempre edificantes, cuyo significado debe acaso buscarse en el deseo de distraer a los dioses y asegurar con hechizos la fecundidad de la reina. Levantada ésta, se partía en pedazos el cuerpo del caballo, y tras misteriosas ceremonias, «asado se ofrecía a Prajāpati». El rito terminaba con el ofrecimiento de dones (dakșinā) a los sacerdotes, obsequio de gran valor (algunos textos hablan de 4.000 vacas y 4.000 barras de oro), y con el baño purificador del soberano ${ }^{18}$ ».

En el Rg-Veda hemos encontrado una detallada descripción de la ceremonia del sacrificio del caballo:

18 A. Ballini, «Las religiones de las India», en P. Tacchi Venturi, Historia de las religiones, Gustavo Gili, Barcelona, 1947, pp. 464-465. 
"Cuando los sacerdotes traen las ofrendas ya preparadas hasta el caballo, al que se ha lavado y decorado con ricos arneses, la cabra de diversos colores que va delante balando se convierte en una ofrenda agradable a Indra y a Pushan.

Esta cabra es la porción que corresponde a Pushan, y conviene a todos los dioses; se la trae primero con el rápido corcel, de modo que Tvashtri pueda prepararla con el caballo como una ofrenda preliminar buena para los manjares del sacrificio.

Cuando en la época de las ceremonias, el sacerdote conduce tres veces en derredor del fuego del sacrificio al caballo, ofrenda consagrada a los dioses; entonces la cabra, la porción de Pushan, acude la primera, anunciando el sacrificio a los dioses.

El que invoca a los dioses, el que oficia en la ceremonia, el que presenta la ofrenda, el que enciende el fuego, el que macera la planta soma, el que dirige la ceremonia y el sabio que preside todos los actos están presentes; llenad los ríos gracias a este sacrificio bien ordenado y dirigido.

Los unos cortan los postes del sacrificio o traen estos postes; otros fijan en ellos los anillos a que está atado el caballo o disponen los vasos en los que se prepara el alimento del caballo: que los esfuerzos de todos respondan a nuestra espera.

Que se cumplan mis deseos tal y como los he formulado, cuando he pedido que el corcel de pelo alisado viniera para satisfacer la espera de los dioses; lo hemos puesto en lugar seguro para que sirva de alimento a los dioses; que los santos sabios ser regocijen.

Que los lazos que retienen la cabeza y las patas del rápido corcel, que las cinchas y las demás partes del arnés, que la hierba que ha sido puesta en su boca y que todas las cosas, estén con él entre los dioses [...].

Si alguna porción de tu cuerpo cae al suelo durante el momento en que está asándose al fuego, haz que no se la abandone en el suelo o sobre la hierba sagrada, sino que se la dé toda ella a los dioses que la deseen.

Que se vuelvan en nuestro favor los esfuerzos de los que vigilan la cocción del cuerpo del caballo, y que digan: "Despide un buen olor, dadnos un poco", que considere como una limosna una porción de la carne del caballo".

El palo hundido en el caldero en que hierve la carne, el vaso que distribuye la salsa, los cubiertos de los manjares, los cuchillos y las agujas, todo, en fin, constituye la dicha (para el caballo).

Que el lugar atravesado por el caballo y que aquel en que se ha caído sobre la hierba; que las cuerdas que han trabado al caballo; que el agua que ha bebido y que la hierba que ha comido, que todo eso sea contigo entre los dioses [...].

El hacha penetra en las treinta costillas del rápido corcel, los (sacrificadores) queridos de los dioses cortan el caballo con habilidad, de modo que los miembros no lleguen a agujerearse [...].

Existe un radiante sacrificador del caballo, el Tiempo; hay dos que lo retienen con fuerza; aquellos de tus miembros que corto en el momento oportuno, los ofrezco preparados en albóndigas de carne sobre el fuego [...].

Ojalá que este caballo pueda traernos una opulencia que nos sostenga, que pueda procurarnos una abundancia de vacas y de caballos y asegurarnos una posteridad numerosa; ojalá que el fogoso corcel pueda procurarnos que nos hallemos exentos de toda malicia, y que este caballo ofrecido para el sacrificio nos procure el vigor del cuerpo ${ }^{19} . »$

19 Vyasa, Los Vedas, Clásicos Bergua, Madrid, 1988, pp. 270-273. 
El otro de los grandes sacrificios védicos era el de soma ${ }^{20}$. Tenía lugar una vez al año, en la primavera, y se le conocía con el nombre de agniștoma («loor a Agni») ${ }^{21}$ y una de las variedades del jyotișțoma («himno de alabanza a la luz»), cuya forma más usual es una «cantata del fuego» ("agni-șțma») e iba precedido de una larga ceremonia de iniciación seguida de otra de purificación ${ }^{22}$ :

«Le precedían cuatro días de preparación y, al romper la aurora, a mediodía y al ponerse el sol del día quinto se celebraba el sacrificio solemne: la más importante y complicada de las ceremonias preparatorias era la consagración o dīkșā, "inten-

20 «Inseparably connected with the worship of Indra and Agni is that of the 'moon-plant', soma, the intoxicating personified drink to whose deification must be assigned a date earlier than that of the Vedas themselves. For the soma of the Hindus is etymologically identified with the haoma of the Persians [...] and the cults at least was begun before the separation of the two nations, since in each the plant is regarded as a god. The inspiring effect of intoxication seemed to be due to the inherente divinity of the plant that produced it; the plant was, therefore, regarded as divine, and the preparation of the draught was looked upon as a sacred ceremony». E. W. Hopkins, The religions of India, Ginn \& Company, vol. I, Nueva York, 1895, pp. 112-113. Cf. A.B. Keith, ob. cit., pp. 327-332.

21 «Una vez por año se realiza el agnistoma, el «elogio de Agni»; tiene lugar en primavera y consiste, aparte de las operaciones preliminares, en tres días de «homenaje» (upasad). Entre las operaciones preliminares, la más importante es la dīksā, que consagra al oficiante y lo hace nacer de nuevo [...] El soma se exprime por la mañana, al mediodía y por la tarde. Con motivo de la extracción del soma a mediodía se distribuyen los honorarios (dāksinā): 7, 21, 60 o 1.000 vacas, y en algunos casos todos los bienes del sacrificante. Son invitados todos los dioses, que toman parte en la fiesta aisladamente al principio y luego todos juntos.

Se conocen otros sacrificios del soma; algunos no duran más que un día, pero otros se prolongan al menos durante doce y en ocasiones un año y teóricamente doce años. Por otra parte, hay ciertos sistemas rituales que fueron asociados a los oficios del soma, por ejemplo, el mahāvrata («gran observancia»), que incluye música, danzas, gestos dramáticos, escenas y diálogos obscenos (uno de los sacerdotes se balancea en un columpio, tiene lugar una unión sexual, etc.). El vajapeya («licor de la victoria») dura de diecisiete días a un año y consiste en el desarrollo de todo un drama mítico-ritual: carrera de caballos uncidos a 17 carros, la «ascensión al sol» a cargo del sacrificante y su esposa, que escalan ceremonialmente el poste sagrado, etc. También la consagración real (rājāsuya) fue incorporada a las celebraciones sacrificiales del soma. También en este caso encontramos unos episodios agitados (simulacro de una incursión de pillaje emprendida por el rey contra una manada de vacas; el rey juega a los dados con un sacerdote y le gana, etc.). Pero el rito tiene por objeto esencialmente asegurar el renacimiento del soberano [...]. Al sacrificio del soma se asoció, aunque potestativamente, otro sistema ceremonial, el agnichayana, "colocación (de los ladrillos para el altar) del fuego». Los textos precisan que «en otros tiempos» se sacrificaban cinco víctimas, entre ellas un hombre [...]. El agnichayana dio origen a ciertas especulaciones cosmogónicas que resultaron decisivas para el pensamiento indio. El sacrificio de un hombre repetía la autoinmolación de Prajapati, mientras que la construcción del altar simboliza la creación del universo». M. Eliade, ob. cit., pp. 233-234.

22 «La estructura general es la de un banquete en el que los dioses -invitados por el sacrificanteacuden a libar en comunión con los fieles (sacrificante y su familia, sacerdotes), el elixir de la inmortalidad (el soma) y a comer la carne de los animales inmolados durante la ceremonia. Se escoge, limita y consagra un terreno apropiado para el sacrificio; en él se instalan los tres fuegos: el dominical, el ofertorio (āhavanīya, donde se vierten las oblaciones), el meridional (dakșina, llamado así porque está destinado a proteger de las influencias nefastas que se supone proceden del sur). A veces, se requieren fuegos auxiliares. Entre los fuegos, se dispone el altar, ligera excavación en la que se deposita una alfombra de hierbas que servirá de litera a los dioses. El número de oficiantes es muy variable, los más importantes (y los únicos estrictamente necesarios) son el oferente (hotar) que vierte la oblación y recita los mantra del Rg-Veda, el acólito (adhvaryu) encargado de las manipulaciones, y sobre todo el brahman que dirige y supervisa la ejecución de la ceremonia, corrigiendo los errores si los hubiere (por eso lleva el nombre de «médico del sacrificio»); el que fuera el más importante de todos los ejecutores lo prueba el hecho de que recibía la mitad del total de los honorarios rituales (dakșinā, llamados así porque estaban colocados al sur del altar), repartiéndose los demás sacerdotes la otra mitad. 
ción [del oferente] de honrar al dios (?)", dando lugar a ritos en los que fermenta el germen del tapas, que llegará más adelante a crueles refinamientos. Ascesis que impone al sacrificador el ceñimiento del cordón sagrado, rasura de cabellos, unción del cuerpo, ayuno riguroso, vigilias prolongadas, hasta el agotamiento, tartamudez, éxtasis contemplativo, maceraciones corporales y sobre todo el caldeamiento del cuerpo (la palabra tapas etimológicamente significa "estar caliente", de la raíz tap), arrimándose a los fuegos o cubriéndose la cabeza: prácticas éstas que remontan a una magia primitiva, "propia de pueblos salvajes o semibárbaros, con el fin de provocar un estado extático apto para entrar en unión íntima con los espíritus y los dioses". La dīkșā termina con un baño (avabhrtha) del sacrificador, de su esposa, de los oficiantes y de los objetos del culto, que aleja toda influencia maligna que pudiera provenir del contacto con los utensilios pertenecientes al sacrificio.

Esta importante ceremonia preparatoria iba acompañada, entre otras, de la colocación de los tres fuegos, elección de los sacerdotes, preparación del altar, con todo lo concerniente a los tallos del soma, etc.

Al clarear el quinto día empezaba el verdadero sacrificio con las presiones (savana) de la planta del soma, denominándose prātar la de la mañana, mādhyamdina la de las doce y trtīya la tercera, de complicadísimos ritos. La primera presión daba principio con la ofrenda de un macho cabrío a Agni, la última terminaba, después del mencionado baño purificador, con la oferta a Mitra y Varuna de una vaca estéril o, en su defecto, de un requesón de leche cuajada.

La planta se prensaba con dos piedras (grāvan) colocadas sobre una piel de buey, "con el fin de recoger el líquido que caía fuera de la piedra que servía de base», método éste normal, como lo demuestra la alusión del ritual al grāvastut, «loador de las piedras». El jugo que rezumaba de los tallos, recogido y trasegado de vasija en vasija, era finalmente purificado a través de un filtro de lana. Una vez transparente (pavamāna), los sacerdotes se lo acercaban a los labios y luego se ofrecía a los dioses: puro a Vāyu y a Indra y juntos, mezclado con leche, harina o miel a las restantes divinidades.

Si bien era propósito del bardo védico celebrar, en las diferentes fases de este

En el sacrificio del soma se trata sobre todo de producir el «néctar de los dioses» con la mayor solemnidad posible (al soma se le llama «rey» y se le trata como a tal). Después de haber comprado ritualmente (o haber fingido comprar) las plantas precisas para su preparación, se llevan en una carretilla al terreno sacrificial, se las recibe, como si se tratara de un huésped distinguido, luego se las aplasta valiéndose de pilones de piedra haciéndolos rodar sobre planchas (a veces se utilizan morteros). El jugo extraído se tamiza mediante una piel de oveja [...]. Agua, leche y a veces también miel se mezclan con el soma antes de que sea bebido. Al mismo tiempo se preparan otros alimentos: pastel de cereales, preparados lácteos, etc. Todos se cuecen con arreglo a un ceremonial minuciosamente descrito y se sacrifican animales (por ejemplo, un chivo, una vaca estéril, etc.) en diversos momentos de la sesión ritual. Todo ello va acompañado por declamaciones y cánticos.

Muchos otros sacrificios, que comportan o no la prensadura de soma, se han adaptado (no sin dificultades) a la norma del jyotiștoma. Los más famosos son la consagración real y el sacrificio del caballo (que dura todo un año y va acompañado de exhibiciones de generosidad casi increíble, que incluían el regalo de cuatro esposas de sangre real a los oficiantes)». J. Varenne, "La religión védica», en H.Ch. Puech (dir.), Las religiones antiguas (Historia de las religiones), Siglo Veintiuno, vol. 2, Madrid, 1986, pp. 394-395. 
importante sacrificio las excelencias de todas las divinidades del panteón índico, por medio de alabanzas dirigidas a ésta o a aquella divinidad, el dios que reunía mayor número de loas era sin duda, Indra, a quien estaba consagrada la segunda presura. Los Maruts y los Ribhus le hacían la corte. Vāyu era apasionado por la presión de la mañana. La recitación (śastra) de los himnos hecha por el hotar y sus asistentes tenían su correspondencia en los cantos (stotra) del udgātar y sus ministros, doce en total, cinco durante la presión de la mañana, cinco en la del mediodía y dos por la tarde» 23 .

La agnicayana (el apilamiento de ladrillos para el altar del fuego) es, entre los ritos solemnes, una ceremonia que reviste especial significado por ser el desarrollo ritual del mito del origen del mundo a partir del hombre primordial. Se reúnen los trozos del gigante primordial descuartizado y se reconstruyen en forma de altar, representación arquitectónica del universo, consiguiéndose así por medio de esta ceremonia ritual la resurrección de Purușa ${ }^{24}$.

\section{LOS SACERDOTES}

El agente indispensable de la actividad sacrificial era el sacerdote. El sacrificio védico contaba con varios tipos de sacerdotes, a saber: el purohita («sacerdote doméstico») y el rtvij («sacerdotes sacrificadores»). El purohita, comisionado por el rey para dirigir la totalidad del culto, ejercía con frecuencia también las funciones de primer ministro real y acabó fundiéndose con el brahmán, el sacerdote que vigilaba sobre todos los otros para el exacto desarrollo y eficacia del sacrificio.

El rtvij («sacerdote sacrificador»), variaban de número según el tipo del sacrificio. El Rg-Veda cita siete sacerdotes destinados a las prácticas del sacrificio: hotar, potar, neșțar, agnidh, pra āstar, adhvaryu y brahmán:

«El Hotar es el "que vierte" [...] a él "incumbe decir de memoria, en cada una de las fases esenciales del sacrificio de Soma, las estancias por las que se celebran las hazañas, el poder y la majestad del dios a quien invocan, invitándole al festín y transmitiéndole los deseos del sacrificante" [...]. El Potar, o "clarificador", tenía antaño un papel importante en las diferentes manipulaciones a que daba lugar el brebaje sagrado, que él debía filtrar y decantar.

${ }^{23}$ A. Ballini, ob. cit., pp. 462-463.

${ }^{24}$ El Rg-Veda recoge el célebre himno del hombre primigenio (Purușa-Sūkta). En él se describe la creación del mundo por los dioses mediante el sacrificio del Purușa: «Al ofrecer los dioses el sacrificio con el purusha como ofrenda, la primavera fue la grasa, el verano la leña, el otoño la oblación. Como sacrificio, sobre la paja ritual consagraron al purusha, que nació en el principio. Con él sacrificaron los dioses, los Sadhyas y los rishis. En este sacrificio, ofrecido totalmente, se recogió la grasa coagulada. Con ella crearon a los animales, que viven en el aire, en los bosques y en las aldeas [...]. De él nacieron los caballos, y las bestias que tienen dentada la boca; y nacieron las vacas, las cabras y los corderos [...]. De su mente nació la luna, del ojo nació el sol, Indra y Agni de su boca, de su aliento nació Vayu. De su ombligo surgió el espacio; de su cabeza se desarrolló el cielo; de sus pies nació la tierra, y de sus orejas las regiones. Así construyeron a los mundos». F. Tola (ed.), Himnos del Rig Veda, Sudamericana, Buenos Aires, Sudamericana, 1968, pp. 267 y $268-269$. 
Al Neshtar o "conductor" correspondía el cumplimiento de un rito que quizá estaba en relación con las virtudes del Soma, y que aparecía como un encantamiento de fecundación.

La función de Agnidh, "atizador del fuego", está claramente definida por su título. Está asociada estrechamente al Adhvaryu, que estaba encargado de la parte material del sacrificio, de la "obra manual".

En fin, el Presastar o "dador de órdenes» y el Brahman, parecen haber sido acólitos del Hotar. Como él, estaban llamados a pronunciar palabras eficaces ${ }^{25}$.»

El coordinador era el hotar («el invocador»), el cual se encargaban de recitar los himnos del Rg-veda en honor de los dioses invitándolos a tomar parte en el ritual sacrificial. Las ceremonias sacrificiales preparación de los altares, manipulación de los útiles del sacrificio, control del fuego eran competencia del adhvaryu, que era también el que recitaba las máximas en prosa contenidas en el Yajur-veda, mientras ejecutaba diversas acciones rituales. El neștar tenía la misión de acompañar a la esposa del sacrificador y de preparar el surā, una especie de aguardiente. El agnìdh era el responsable de avivar el fuego. El udgātar, que habitualmente se presentan en número de tres y que el Rg-veda todavía no menciona, salmodiaba o cantaba canciones versificadas con las melodías del Sāmaveda. De la buena entonación del canto dependía la eficacia del sacrificio. El potar, «purificador del soma». Por último, el brahmán (más tarde llamado brāhmanācchamsin), «vigilante del sacrificio», relacionado con el Atharva-veda, era el encargado de cuidar la rigurosa ejecución de todos los detalles prescritos.

25 P. de Felice, Venenos sagrados embriaguez divina, Felmar, Madrid, 1975, pp. 198-199. 